\title{
Speech and other functions after left (dominant) hemispherectomy
}

\author{
AARON SMITH \\ From the Neuropsychological Laboratory, Nebraska Psychiatric Institute Division of Neurology, \\ University of Nebraska College of Medicine, Omaha, Nebraska, U.S.A.
}

The development of hemispherectomy for glioma (mostly in adults) by Dandy (1928) and later for infantile hemiplegia by Krynauw (1950) permitted comparisons of effects of removal of either hemisphere on both the adult and young brain. Reviews of over 300 cases of hemispherectomy (e.g., White, 1961; McFie, 1961) reflect the 'functional plasticity' of the young brain. Continuing development of higher and lower level cerebral functions after right or left hemispherectomy in children with gliomas as well as infantile hemiplegia has been reported by most writers. A 10-year-old left-handed girl (Gardner Karnosh, McClure, and Gardner, 1955) and a 14year-old right-handed boy (Hillier, 1954) were reported living 53 and 27 months respectively with functional speech after left hemispherectomy for glioma. Obrador (1964) described transfer of language to the 'non-dominant' hemisphere as the rule up to the age of 15 . However, there is general agreement that in the adult this plasticity is largely lost and that dominant hemispherectomy is to be discouraged.

Right hemispherectomy in the adult for glioma has been much more frequently reported. This is followed by the expected severe left hemiplegia and hemianopia but ability to walk was often acquired, and some patients developed useful movement of the left arm.

The greater reluctance to remove the left hemisphere in adults reflects widespread beliefs that the integrity of various dominant hemisphere structures is necesary for many functions including receptive and expressive language (oral and written), 'higher' mental functions (Smith, 1966), control of right and left-sided purposeful movements (Liepmann, 1905), arithmetical reasoning, and discrimination of colours (Hécaen and Ajuriaguerra, 1964). Numerous cases with left-sided focal lesions have been cited to support these beliefs. Continuing survival over seven months after left hemispherectomy in the case described below provided an opportunity to study the capacity of the minor hemisphere to maintain or acquire speech and other non-language cerebral functions.

\section{CASE REPORT}

Beginning in November, 1964, E.C., a 47-year-old man, experienced increasingly frequent attacks of speechlessness associated with seizure activity in the right arm and right face. Neuropsychological studies indicated rightsided manual and ocular dominance. E.C. wrote, threw, hammered, with and consistently preferred the right hand in skilled and unskilled manual performances. His mother and father, two brothers, and two sons are right-handed. On 31 March 1965, a neoplasm, later identified as a glioblastoma multiforme, was removed from the left sensori-motor region. In addition to speech disorders manifested as one of the initial symptoms of tumour, a moderate post-operative expressive aphasia with increased difficulty in word finding and in articulation confirmed left hemispheric dominance for language functions.

E.C. was readmitted to the Veterans Administration Hospital in November 1965, with a chief complaint of progressive weakness of the right arm and minimal weakness of the right leg. There was no evidence of receptive aphasia and although speech was slow and deliberate, if given time he would 'find the words' he sought for in efforts to express himself. Extensive diagnostic studies confirmed the recurrence or continuing growth of vestiges of a malignant neoplasm and a total left hemispherectomy was performed by Dr. C. W. Burklund on 7 December 1965. (Summarizing Dr Burklund's surgical notes, the corpus callosum was split lateral to the anterior cerebral artery, all branches of the artery being coagulated and divided. After cutting through the thalamus posteriorly and the basal ganglia anteriorly, the entire hemisphere (Fig. 1) was removed in one piece.) Austin and Grant (1955) have called attention to differences in the various surgical procedures employed in hemispherectomies and the extensive secondary degeneration of remaining ipsilateral structures following removal of the right hemisphere. The isocortex, all four left cerebral lobes, limbic forebrain and basal ganglia were completely removed in E.C. in an effort to assure that no malignant vestiges remained.

Immediately following hemispherectomy, the patient had a right hemiplegia and right hemianopia. In addition to initial symptoms of tumour, severe receptive and expressive aphasia following hemispherectomy confirmed that the left hemisphere was 'dominant' for language. Ability to follow simple verbal commands indicated normal hearing and some comprehension of 


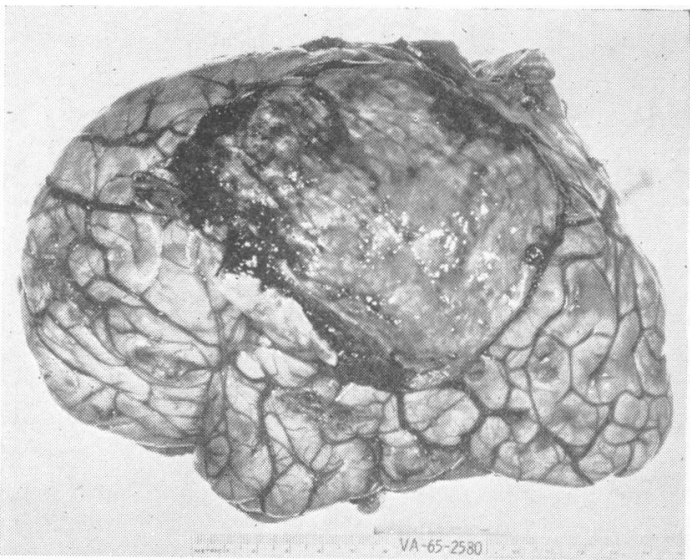

FIG. 1a

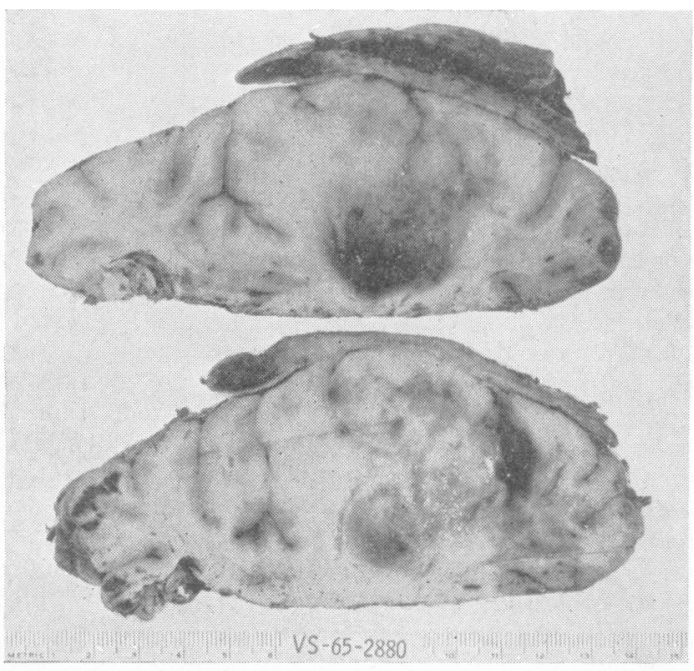

FIG. 1c

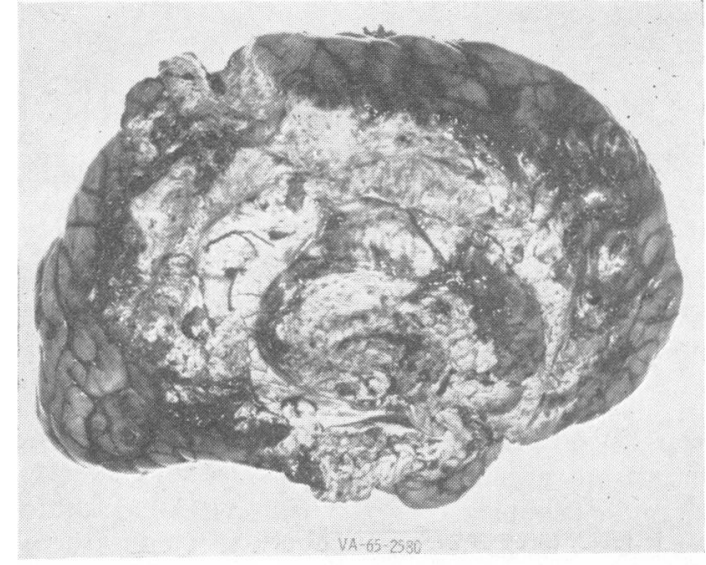

FIG. 1b

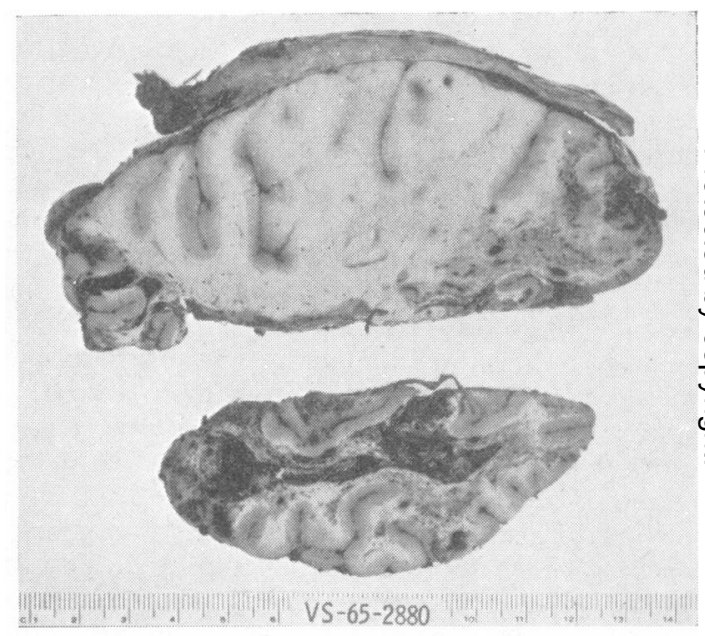

FIG. $1 \mathrm{~d}$

FIG. 1, a, b, c, and d. Illustrations of the removed left cerebral hemisphere. (a) Lateral view of left hemisphere; (b) medial aspect of left hemisphere; (c) section of left hemisphere showing neoplastic proliferation; $(d)$ sectioned through another plane.

speech. Audiometric studies completed six months after surgery (31 May 1966) showed normal hearing from 250 to 2,000 c.p.s. in each ear and a moderate bilateral loss at 4,000 c.p.s. in responses to pure tone stimuli delivered through a hand-held receiver.

SPEECH E.C.'s attempts to reply to questions immediately after operation were totally unsuccessful. He would open his mouth and utter isolated words, and after apparently struggling to organize words for meaningful speech, recognized his inability and would utter expletives or short emotional phrases (e.g., 'Goddamit!'). Expletives and curses were well articulated and clearly understandable. However, he could not repeat single words on command or communicate in 'propositional' speech until 10 weeks post-operatively (15 February 1966) when he replied to a nurse (asking if he had had a BM), 'What does BM mean?'. Although E.C. is unable to speak voluntarily most of the time, occasional propositional speech continues to increase, along with ability to repeat successfully longer sentences on command in fewer trials.

Tested for comprehension in the sixth post-operative month (16 May 1966) with the question, 'Is it snowing outside?', E.C. smilingly replied, 'What do you think I am ? A mind reader ?'. Two weeks later I visited him at home. When his wife asked why he hadn't told her of my plan to visit, he promptly replied, 'I forgot'. I later asked him how long he had lived in his house and he 
instantly replied, 'About seven years' (correct). Asked on 30 June 1966 if he felt the vibrations of a tuning fork in his right elbow, he replied 'just traces'. Expressive speech, however, remains severely impaired in the eighth month after hemispherectomy.

SINGING In the fifth postoperative month, E.C. showed sudden recall of whole old familiar songs (e.g., My Country 'Tis of Thee, Home on the Range, church hymns). In the seventh month after surgery, he sings with little hesitation and few errors in articulation.

WRITING Learning to print single words with his left hand required several practice sessions in occupational therapy. Asked to write the name of a pictured object on 31 May 1966, he correctly said and printed the word cow. However, there has been little subsequent improvement in writing to date.

VERBAL COMPREHENSION Improving verbal comprehension was reflected in increasing scores in the Peabody picture vocabulary test. On 25 January 1966, E.C. slowly but correctly selected four of the first six items I named from six pages, each with four pictures to choose from, before indicating that he was tired. On 3 June 1966 he correctly selected 85 of 112 items. The marked improvement in scores shows increasing capacity for prolonged testing and attention span as well as increasing verbal comprehension which was evident in conversation with him and performances on other psychological tests.

READING AND COLOUR DISCRIMINATION On 25 May 1966
I placed five coloured pens (red, blue, green, yellow, and black) before E.C. and asked him to pick up the yellow pen. When he selected the red one at his extreme left, I carefully explained this was a test to see if he could recognize colours and he was to pick up only the coloured pen I named. He nodded vigorously, and proceeded to select correctly the randomly named colours on all nine remaining trials. The test was repeated with colours to be selected printed on a sheet of paper instead of spoken. E.C. was correct in all five trials on this test. Colour blindness was ruled out by correct performances on the Ishahara test.

NON-LANGUAGE MENTAL FUNCTIONS Re-examinations with the W.A.I.S. performance subtests were supplemented with other tests. Comparisons of scores before and six months after hemispherectomy (Table I) indicate initial impairment and subsequent recovery of preoperative levels in the performance subtests. (Performance I.Q.s of 108 and 104, prorated, in May and June 1966 vs. 100 before craniotomy in February 1965.)

Memory for visual motor patterns tested by the Knox cubes on 25 January 1966 showed correct responses to the first three patterns on the first trial, to the fourth on the second trial, and failure on all three trials for the fifth pattern. On 3 June 1966, E.C. correctly responded to all five patterns on the first trial.

The Porteus maze, designed to measure 'foresight' and non-verbal intelligence, showed scores of $12 \frac{1}{2}$ years on 25 May 1966 and 15 years on 3 June 1966 with E.C. using his left hand.

Arithmetical reasoning also improved markedly. On 25 January 1966 E.C. picked up correct numbers of

\section{TABLE I}

RAW PSYCHOLOGICAL TEST SCORES BEFORE AND AFTER EXCISION BIOPSY (ON 31 MARCH 1965) AND HEMISPHERECTOMY (ON 7 DECEMBER 1965)

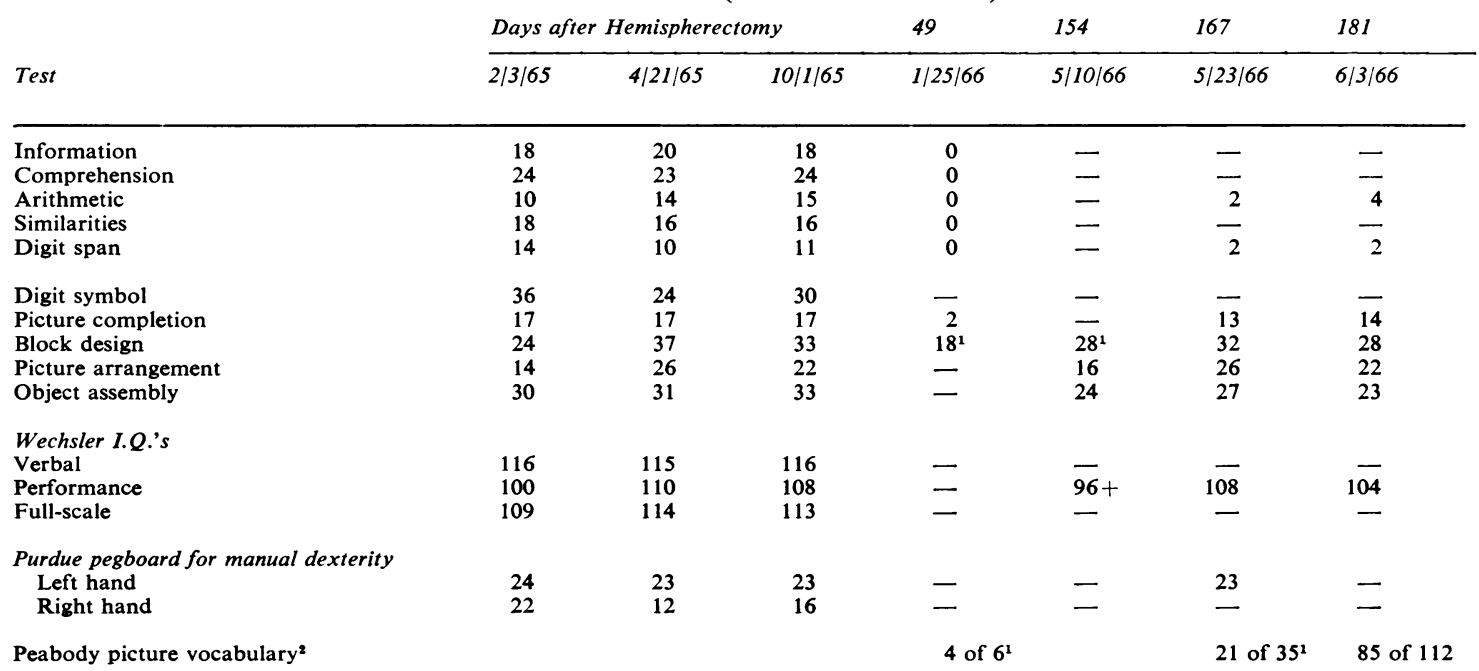

1Testing stopped when patient indicated he was fatigued.

'The Peabody picture vocabulary test and scores in other tests administered before and after hemispherectomy (not shown above) also reflected continuing improvement with continuing survival. Performances on the Peabody picture showed more frequent errors in identifying pictures of activities than of objects. The last six correctly identified pictured on 3 June 1966 were: precipitation, hieroglyphic, orate, cascade, illumination and embossed. 
blocks from one to five on command, but could not select correct answers for simple addition problems from four choices. On 27 May 1966 E.C. selected correct answers for all 10 problems of addition (sums of three to five numbers of one and two digits) from four possible number choices. On 31 May 1966 he similarly selected correct answers for all three problems in simple multiplication, all three in subtraction, and two of three in division. Concrete calculation ability was tested on 2 June 1966 by asking E.C. for specific sums of money to be assembled from coins and a single dollar placed before him in a pile. He correctly assembled 13 of 18 amounts from 19 cents to $\$ 1.17$.

E.C. could not identify objects placed in his right hand, but made no errors in 14 selections of different objects (eraser, spoon, key, nickel, pipe reamer, typewriter eraser, matchbook) placed in his left hand. A left-hand dexterity test on 3 June 1966 with the Purdue pegboard was almost identical with normal performances before hemispherectomy. Ability to follow verbal commands requiring other purposeful movements of the left hand showed no evidence of 'sympathetic dyspraxia'.

Marked variability in susceptibility to fatigue, distractability and attention span, reported following right hemispherectomy in similar cases (Gardner et al., 1955; Mensh, Schwartz, Matarazzo, and Matarazzo, 1952), was also observed in E.C. shortly after hemispherectomy, but gradually decreased. 'Loss of personality values' or bizarre behaviour reported after similar cases with right hemispherectomy (Gardner et al., 1955), however, was not observed in E.C. Affective reactions and general behaviour I have observed before and after hemispherectomy were appropriate, and consistent with his wife's report of no noticeable change in emotional responses or in a basically well-balanced personality.

MOTOR FUNCTIONS Early post-operative complications, including a thrombophlebitis in the lower right extremity and anaemia, necessitated prolonged bed rest during the first post-cperative month. Although most reported cases surviving right hemispherectomy show recovery of sufficient left-sided motor functions to permit walking unaided, possible similar recovery of right-sided motor functions in E.C. was complicated by calcification in the muscles of the right lower extremity and probably in the 'frozen' right shoulder which is painful when moved. However, E.C. shows slight progress in walking in the parallel bars. He has been consistently able, since the third post-operative month, to move the fingers on his right hand on command. In the seventh post-operative month, he also demonstrated ability to elevate his right foot slightly on command. The presence of contralateral motor functions following right and left hemispherectomy is consistent with Jackson's views of unequal but bilateral cerebral representation of these and other functions described above.

GENERAL BEHAVIOUR E.C. can tell the time, moves about independently in his wheel chair, keeps appointments in the Omaha Veterans Administration Hospital on other floors (requiring use of the automatic elevator) without being reminded, and has been going home at weekends since 26 March 1966. Libidinal drives were reported to be normal.

\section{COMMENT}

Because the range of individual variability in hemispheric functions is unknown, the representativeness of the above findings cannot be assessed. Zangwill observed that, like handedness, "cerebral dominance is in all probability a graded characteristic, varying in scope and completeness from individual to individual' (Zangwill, 1960, p. 27). The findings in this single case, however, are strikingly consistent with observations in the only two reported similar cases (Zollinger, 1935; Crockett and Estridge, 1951), although severely impaired, speech and verbal comprehension were present immediately after left hemispherectomy in all three cases. Since these functions are not abolished, and since speaking, reading, writing, and understanding language show continuing improvement in E.C. after left hemispherectomy, the right hemisphere apparently contributes to all these functions, although in varying proportions (i.e., receptive language functions were initially less impaired and have shown greater recovery than expressive language). Thus hemispheric functions would seem to differ quantitatively rather than qualitatively.

The ability to recall and sing old songs suggestso that the right hemisphere plays an important role in musical memory and in the neuromotor processes ofo singing. The increasing use of propositional speech and verbal comprehension was also reported in the only two similar cases of left hemispherectomy for glioma in adults cited above, and indicates that in addition to comprehension of speech, the right hemisphere alone is capable of more than the automatic, primitive utterances first described by Jackson (1958).

\section{SUMMARY}

A case is reported of a 47-year-old right-handed, right-eyed man in which the left (dominant) cerebral hemisphere was removed for glioma. Differences in the amount of initial impairment and recovery of speech and other cerebral functions were studied during the first seven months after hemispherectomy. Since the findings of continuing recovery of language functions were consistent with results in the only two other reported similar cases, it is concluded that the minor hemisphere has considerable capacity even in the adult to organize language and other nonlanguage mechanisms.

The cooperation of E.C., the patient, Dr. C. W. Burklund, who performed the operation and participated in 
this research, of Drs. S. J. Dutch (neurology), R. J. Ellingson (electroencephalograph), J. McBeath (neuropathology), J. Wiley, and N. Timmons (audiometry), and many colleagues at the Omaha Veterans Administration Hospital is gratefully acknowledged. Mr. Don Moran's assistance in extensive testing was especially appreciated. This research was supported by U.S.P.H.S. research grant HD-00370. Professor W. R. Russell's critical review and helpful suggestions are gratefully acknowledged. Thanks are also due to the medical illustrations section of the Omaha Veterans Administration Hospital for supplying the photographs.

\section{REFERENCES}

Austin, G. M., and Grant, F. C. (1955). Physiologic observations following total hemispherectomy in man. Surgery, 38, 239-258.

Crockett, H. G., and Estridge, N. M. (1951). Cerebral hemispherectomy. Bull. Los Angeles neurol. Soc., 16, 71-87.

Dandy, W. E. (1928). Removal of right cerebral hemisphere for certain tumors with hemiplegia. J. Amer. med. Assn, 90, 823-825.

Gardner, W. J., Karnosh, L. J., McClure, C. C. Jr., and Gardner, A. K. (1955). Residual function following hemispherectomy for tumour and for infantile hemiplegia. Brain, 78, 487-502.

Hézaen, H., and Ajuriaguerra, J. de (1964). Left-Handedness. Grune and Stratton, New York.
Hillier, W. F. (1954). Total left hemispherectomy for malignant glioma. Neurology (Minneap.), 4, 718-721.

Jackson, J. H. (1958). Selected Writings of John Hughlings Jackson, edited by J. Taylor. Basic Books, New York.

Krynauw, R. A. (1950). Infantile hemiplegia treated by removing one cerebral hemisphere. J. Neurol. Neurosurg. Psychiat., 13, 243-267.

Liepmann, H. K. (1905). Die linke Hemisphäre und das Handeln. Münch. med. Wschr., 52, 2322-2326, 2375-2378.

McFie, J. (1961). The effects of hemispherectomy on intellectual functioning in cases of infantile hemiplegia. J. Neurol. Neurosurg. Psychiat., 24, 240-249.

Mensh, I. N., Schwartz, H. G., Matarazzo, R. R., and Matarazzo, J. D. (1952). Psychological functioning following cerebral hemispherectomy in man. Arch. Neurol. Psychiat. (Chic.), 67, 787-796.

Obrador, S. (1964). Nervous integration after hemispherectomy in man. In Cerebral Localization and Organization, edited by G. Schaltenbrand and C. N. Woolsey, pp. 133-154. University of Wisconsin Press, Madison.

Smith, A. (1966). Intellectual functions in patients with lateralized frontal tumours. J. Neurol. Neurosurg. Psychiat., 29, 52-59.

White, H. H. (1961). Cerebral hemispherectomy in the treatment of infantile hemiplegia. Review of the literature and report of two cases. Confin. neurol. (Basel), 21, 1-50.

Zangwill, O. L. (1960). Cerebral Dominance and Its Relation to Psychological Function. Oliver and Boyd, Edinburgh.

Zollinger, R. (1935). Removal of left cerebral hemisphere. Report of a case. Arch. Neurol. Psychiat. (Chic.), 34, 1055-1064. 